\title{
The Uncertain Future of Banking: People and Change Management
}

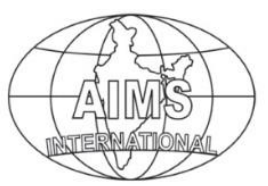

DOI: $10.26573 / 2021.15 .2 .5$

Volume 15, Number 2

May 2021, pp. 137- 142

\author{
Twinkle Trivedi \\ SLIBM \\ (twinkletrivedi1@gmail.com)
}

\begin{abstract}
The recent time has witnessed remarkable and radical changes in industries worldwide. Banking is no exception and perhaps in the phase of a major transformation. The traditional role of bank is changing. Technological innovations continuously emerge; enabling new management techniques and innovative business models. The objective of this study was to identify the factors influencing positive attitude of employees towards change. The primary data was collected through a structured questionnaire and convenience sampling technique was used. The analysis of the data can be used to formulate the change management strategies.
\end{abstract}

Keywords: Banking, Change Management, Transformation

\section{Introduction}

The recent time has witnessed remarkable and radical changes in industries worldwide. Banking is no exception and perhaps in the phase of major transformation. The traditional role of bank is changing. Technological innovations continuously emerge; enabling new management techniques and innovative business models. The variety of technical changes, possibilities and innovations, their demand for high implementation speed and their extensive spillover effects for the organization are continuously taking place in the organization which leads to interrupted change process, change process overlap and the organization hence finds itself in a continuous process of change. Banking is no exception. Banking is undergoing digitalization process. Change process in digital era to be successful has to be transition of new process, task and skills in existing corporate culture. While implementing organizational changes, it does not matter how corporate strategies, organizational structure or culture change but how to make employees accept those changes (Kotter et al., 2002). Managers, therefore, need to be aware of the impact of change on employees' thoughts, feelings and behavior, in order to enhance the support of employees and increase the success in the process of change.

According to Backer (1995), individual readiness for change is involved with people's attitude and intentions regarding extent to which changes are needed and their perception of individual and organizational capacity to successfully make those changes. Readiness is a state of mind about the need. It may change due to changing circumstances like type of change introduced, culture of the organization, characteristic of potential adopters and change agents. Hence interventions to 
enhance readiness are possible. If generating a shared sense of readiness sounds difficult, that is because it probably is. This might explain why many organizations fail to generate sufficient organizational readiness and, consequently, experience problems or outright failure when implementing complex organizational change. Although organizational readiness for change is difficult to generate, motivation theory and social cognitive theory suggest several conditions or circumstances that might promote it.

India has emerged as one of the world's largest fintech markets. We have traditional banks and startups that are investing heavily on digital experiences, which have helped to focus on digital banking. Digital banking will bring a new revolution in India which would bring four critical shifts within the banking landscape. Customer expectations have risen over the past decade across all businesses, including banks. They expect the interactions to be intuitive, seamless and straight forward. Banks have been investing to meet these expectations but have struggled to keep pace. Customer self-service in the banking industry is a significant component of customer experience. With increased mobility, customers are now quickly accessing their banks via their smart phones. With the surge of financial technology companies, competition rose among the traditional banks that identified the need to use technology to remain in the race. Digital banks, with their tech stack, have numerous data points to provide a seamless experience to customers. Superior data and analytics will now be the game changers in building deeper and stronger relationships with customers. The competition in banking is only going to intensify further in the coming few years and banks will have to take bolder steps now to establish a formidable position in the market. The digital banks that capitalize on the current shifts in the market will be at an advantage in their core markets and will have the ability to start competing across the world.

\section{Literature Review}

Researchers have attempted to provide insights into change and change management and help organizations successfully implement change. A successful change involves three different phases: unfreezing, moving/change and refreezing (Lewin, 1947). Many researchers have described steps to be employed for implementation of organizational changes (Armenakis et al., 1999; Kotter, 1995). However simply following the steps of change processes doesn't necessarily guarantee successful change implementation. Change agents and managers must also be conscious of several factors to the changing organization. Three factors classified as content, context and process factors are common to all change efforts (Armenakis \& Bedeian, 1999). Another important factor that cannot be ignored in change research is individual differences. Bray (1994) called for an increase in organization change research focusing on the micro-level factors influencing successful change. Change success may hence lie within the psychological predisposition of individual experiencing the change (Judge et al., 1999).

The success of organizational change is often determined by employee attitudes and beliefs towards the change (Beer \& Walton, 1990). Attitudes reflect a person's tendency to feel, think or behave in a positive or negative manner towards the object of the attitude (Arnold et al., 1995). Individual's perception towards the new situation primarily affects organizational change objectives. Many researchers like 
Eby et al. (2000), Kotter (1996) and Martin (1998) focused on positive attitude to promote effective change programs.

\section{Methodology}

The research design of the present study is descriptive in nature. The purpose of the study is to study an impact of individual and workplace factors on employee readiness for organizational changes. The scope and population of the present study is defined and limited to branch managers of private and public sector banks in Gujarat. This research focuses to identify the factors influencing positive attitude of employees towards change. The sampling method used in this study is convenience sampling. The total number of managers taken for the study is 500 . Out of the 500 questionnaires filled 480 were usable. For measuring employee readiness for change partial scale by Holt, 2007 was adopted. Preliminary quantitative research is carried out to undertake preliminary assessment of the reliability of the designed scales and make adjustment. The concepts of the study are measured by available scales. There are five concepts with a total of 20 observed variables. Seven-level Likert scale from 1 (strongly disagree) to 7 (strongly agree) is employed to measure the variables. 20 items in the instrument from item 1 to 20 brings the information about the cognitive and affect aspects of individual's readiness for change. These questionnaire items have been applied by Holt et al. (2007). Further, items from 17-20 adapted from the study of Bouchenooghe et al. (2009) measures affect element of individual change readiness and provides information about the emotional readiness. Holt (2007) discusses the development and evaluation of an instrument that can be used to gauge the Readiness for Organizational Change at an individual level and the results suggest that the Readiness for Change is a multidimensional construct influenced by beliefs among employees that (a.) they are capable of implementing a proposed change (i.e., change specific efficacy, (b) the proposed change is appropriate for the organization (i.e., appropriateness), (c) the leaders are committed to the proposed change (i.e. management support) and (d) the proposed change is beneficial to organizational members.(i.e. personal valence.).Analysis tool used were factor analysis using SPSS.

\section{Data Analysis}

A total of 20 independent variables after the preliminary research are included in factor analysis. KMO index equal to 0.892 and sig. $=0.000$ illustrates that factor analysis is appropriate for the present data. The factor analysis is based on Eigen value parameter; only those factors going with Eigen value greater than 1 are retained in the model now that after standardized, each original variable has a variance equal to 1 . Varimax method is employed to minimize the number of variables with high factor loadings in the same factor. Factor analysis results are presented in Table 1.

From the theoretical model with four factors affecting employee readiness, the study develops five factors, including appropriateness of change, management support, self-efficacy, valance and emotional readiness. The above extracted factors explain $59.50 \%$ of the observed variables. The values of factor loadings range from 0.575 to 0.833 and are generally acceptable. Cronbach's Alpha analysis shows that the reliability of the scales is satisfactory. The Cronbach alpha values are given below in Table 2. 
Table 1 Rotated Component Matrix

\begin{tabular}{|l|c|c|c|c|c|}
\hline \multirow{2}{*}{} & \multicolumn{5}{|c|}{ Component } \\
\cline { 2 - 6 } & 1 & 2 & 3 & 4 & 5 \\
\hline Appr1 & .709 & & & & \\
\hline Appr2 & .699 & & & & \\
\hline Appr3 & .679 & & & & \\
\hline Appr4 & .514 & & & & \\
\hline Appr5 & .608 & & & & \\
\hline MS1 & & .512 & & & \\
\hline MS2 & & .433 & & & \\
\hline MS3 & & .572 & & & \\
\hline MS4 & & .546 & & & \\
\hline SE1 & & & & & .711 \\
\hline SE2 & & & & & .737 \\
\hline SE3 & & & & & .723 \\
\hline SE4 & & & & & .575 \\
\hline Val1 & & & & .805 & \\
\hline Va12 & & & & .844 & \\
\hline Val3 & & & & .853 & \\
\hline ER1 & & & .672 & & \\
\hline ER2 & & & .775 & & \\
\hline ER3 & & & .779 & & \\
\hline ER4 & & & .625 & & \\
\hline Extraction Method: Principal Component Analysis. \\
Rotation Method: Varimax with Kaiser Normalization. \\
\hline a. Rotation converged in 9 iterations. & & \\
\hline
\end{tabular}

Table 2 Reliability of Study Variables

\begin{tabular}{|l|c|c|}
\hline \multicolumn{1}{|c|}{ Variables } & Cronbach's Alpha & No of items: \\
\hline Appropriateness & .762 & 5 \\
\hline Management Support & .810 & 4 \\
\hline Self Efficacy & .609 & 4 \\
\hline Personal Valance & .825 & 3 \\
\hline Emotional Readiness for change & .755 & 4 \\
\hline
\end{tabular}

\section{Results and Discussions}

This research contributes a new model of employee's attitudes and behavioral tendencies in organizational change within banks. The application of the research model to examine and analyze new datasets will provide useful information for local as well as foreign businesses in need of reforms. The results support administrators 
with the management of changes, allowing organizational changes to yield positive results within banks of India. First factor of the employee readiness for change comprises of the highest no of the items illustrating the fact that the bank employees highly believe the changes planned and implemented by their banks are appropriate for their organization. Second Factor of the employee readiness for change has four variables grouped in it. The variables explain management support and commitment towards change. The third factor highlights the fact that bank's employee believe they can handle the change effectively. The employees believe they have the skill required to deal will the changes and can handle the change with ease. Next factor is personal valance and it is composed of the variables loss of status and disrupts the relationships at bank. Emotional readiness for change represents the affect element of change readiness attitude of bank employees.

\section{Conclusions}

The major contribution of this research is in the area of understanding the factors of employee readiness for change pertaining to the Indian Banking Sector. Theoretically, this research has contributed to the existing body of knowledge pertaining to the factors of employee change readiness by incorporating new information through empirical research. An empirical model of employee readiness for change has been developed and it has added richness to the employee readiness for change constructs studied so far in the context of Banking Sector. As our economy is dominated by the service sectors \& banking has been one of the leading contributing industry and hence employee readiness for change is a key instrument for the banking players to design change management strategies. This indicates the importance of the employee change readiness as an important construct for banks. Higher employee readiness for change facilitates successful change implementation and positive change related behavior. The study has focused on the digitalization changes in retail banking. Future research $\neg$ may be conducted in the different types of the changes within bank such as structural, process, and technological changes to see whether the empirical model of the employee readiness for change developed in the study is consistent in the different changes. In order to improve the level of acceptance of the type of changes and their readiness toward change among the employees in the private and public sector banks, various Organizational Change interventions should be planned and implemented by change agents. Change management of strategies should start with developing a vision and change skills. There are different models of change management as is evident in the literature review. Thus, there is no single universal way of managing change. The people factor is portrayed as the most important factor in the management of change in organizations. Thus, it is important for the managers to be careful on how they handle the employees in the organization. Communication of any change the organization intends to undertake is very important.

\section{References}

1. Armenakis, A. A., \&Bedeian, A. G. (1999). Organizational change: A review of theory and research in the 1990s. Journal of management, 25(3), 293-315 
2. Armenakis et al. (1993). Creating readiness for organizational change, Human relations, 46(6)681-703

3. Bouckenooghe, D., Devos, G., \& Van den Broeck, H. (2009). Organizational change questionnaire-climate of change, processes, and readiness: Development of a new instrument. The Journal of psychology, 143(6), 559-599.

4. Backer, T. E. (1995). Assessing and Enhancing Readiness for Change: Implications for Technology Transfer, In T. E. Backer, S. K. David and G. Soucy ed., Reviewing the Behavioral Science Knowledge Base on Technology Transfer, Rockville, MD: National Institute on Drug Abuse, pp. 21-41.

5. Holt, D. T., Armenakis, A. A., Feild, H. S., \& Harris, S. G. (2007). Readiness for organizational change: The systematic development of a scale. The Journal of applied behavioral science, 43(2), 232-255

6. Kotter, J.P. \& D.S. Cohen (2002), The Heart of Change: Real-life Stories of How People Change Their Organizations, Harvard Business Review PressKotter, J. P. (1995). Leading change: Why transformation efforts fail.

7. Kotter, J. P. (1996). Leading change. Harvard Business Press.

8. Weber, P.S. \& Weber, J.E. (2001).Changes in employee perceptions during organizational change. Leadership and Organization Development Journal, 22(5-6), 291

\section{About Our Author}

Twinkle Trivedi possesses more than 15 years of experience in academics and research. She is currently working as assistant professor with Som-Lalit Institute of Business Management, Ahmedabad. Her areas of interest include organizational behavior, human resource management and marketing research among others. She has completed her doctoral research on Impact of Workplace and Individual Factors on Employee Readiness for Change within Banks of Gujarat. She has contributed several papers in reputed national and international management journals. She has also presented papers in national and international conferences. As a part of pursuit for academic excellence, she has attended several seminars, workshops and conferences related to statistical analysis, research methodology and teaching methodology. She has also guided several post graduate students in their internship and research projects. 